\title{
Health services research: what is being done, why do it at all?
}

\author{
E.G. Jessop \\ Wessex Institute of Public Health Medicine, Dawn House, Romsey Road, Winchester, Hampshire \\ SO22 5DR, UK
}

\section{Why do it?}

There are, I suppose, two ways of running a health service: guesswork or knowledge. National Health Service (NHS) reforms, closure of institutions, moves to day care, centralization of services: all of these changes in the way we run health services should be made on the basis of knowledge not guesswork. And if politics dictate that the changes are made in the absence of knowledge, then at least we should know what effect the changes have had. This is the fundamental justification of health services research: the need to acquire knowledge of how best to run health services.

A pair of recent publications have provided a classic example of the need for knowledge to precede changes in organization. The Government has rightly identified coronary heart disease as a major public health problem and one amenable to preventive action. ${ }^{\prime}$ There was, however, little evidence for the chosen strategy of heavy reliance on general practitioners and their staff to reduce this public health problem. Informed opinion suggested that this strategy was doomed to failure ${ }^{2}$ and this has been largely confirmed by two randomized controlled trials. ${ }^{3.4}$

Research in the United States has placed a question mark over another popular way of delivering a service: geriatric day hospitals. ${ }^{5}$ As the authors note, 'the support of a multi-site, multiyear randomized controlled trial ensured the integrity of the design and sufficient statistical power to place a high degree of confidence in the major findings', which were that there was no difference in outcomes, physically, psychologically or socially, nor in survival, between patients assigned to day care and their counterparts assigned to customary care; nor was there any benefit to their carers.

Other policies have fared rather better under scientific evaluation, albeit an evaluation conducted many years after adoption of the policy. A

Correspondence: E.G. Jessop, D.M., F.F.P.H.M. Received 15 April 1994 series of studies at the Friern Barnet hospitals ${ }^{6}$ has confirmed many of the expected benefits of moving long-stay psychiatric patients out of their institutions into houses. These examples show why health services research is needed but beg the question of what research is being done.

\section{What is being done}

\section{Outcomes research}

A major field of research is investigation of the outcome of treatment. Although most clinicians have some interest in whether or not their patients get better, health service researchers seem to claim for themselves outcomes research. To some extent this is justified by the difficulty those on a battlefront have in knowing how the war is going; a recent paper from Maryland ${ }^{7}$ looked at the shift to doing cholecystectomies endoscopically and concluded that despite the undoubted clinical advantage of laparoscopic cholecystectomy (operative mortality went down by $33 \%$ ), the number of people killed each year by the procedure had stayed the same because of the number of operations done had risen by $28 \%$.

Much effort has been expended in an attempt to understand the large differences in outcome between different doctors, teams and hospitals. The research literature continues to support the obvious contention that for complex procedures and rare conditions, a well-practised team will produce better results than occasional performers, ${ }^{8,9}$ but for more common conditions the evidence is conflicting. ${ }^{10,11}$ Do hospitals with high mortality rates give worse treatment or is it just that they admit sicker patients ${ }^{12}$ (or indeed do both factors operate $\left.{ }^{13}\right)$ ? Adjusting for case mix often reduces $^{12,14}$ and may even reverse ${ }^{15}$ prima facie judgements about relative performance. Acquiring a detailed understanding of the relationship between volume and quantity - its relevance to different conditions and procedures, the thresholds at which the effect begins to operate, whether 
adherence to protocols overcomes the deficit of low volume hospitals ${ }^{16}$ - all of this is of immense importance for the organization of health services, since the general finding that low volume equates with poor quality suggests that the 1960 s concept of a general hospital is now outdated and should be replaced with a series of specialist centres.

\section{Quality of life}

The old aphorism 'The operation was a great success but the patient died' drives another strand of health services research, into the patient's quality of life. A vast number of quality of life questionnaires are available, most of which remain unvalidated. ${ }^{17}$ The Nottingham Health Profile ${ }^{18}$ is an exception that used to be the UK standard. An example of its power is given in a series of graphs that document the tremendous symptomatic improvement afforded by cardiac transplant. ${ }^{18}$ It is being superseded by SF36, developed in the USA for the Medical Outcomes Study. ${ }^{19,20}$ These generic scales may miss the most characteristic problems associated with a disease (for example, intractable diarrhoea associated with AIDS) ${ }^{21}$ which leaves room for the development of disease-specific questionnaires. There is particular interest in developing good questionnaires for outcome in physical disability $^{22-24}$ to match the well-developed scales available for mental disability (for example, Conway et $a l .{ }^{25}$ ).

\section{Documenting variation and trends}

The epidemiological trio of time, place and person continue to provide some of the knowledge base required to run health services well. Geographical variations in hospital admission rates continue to attract attention ${ }^{26}$ and to defy explanation, but one thing is clear: with some rare exceptions, ${ }^{27,28}$ variations in admission rates are unrelated to variation in the incidence or prevalence of disease. For a service that is supposed to be based on need, this is a challenge. Recent research, particularly in the UK, has moved beyond the statistical explanations to focus on the psychology of why general practitioners refer and hospital doctors admit, ${ }^{29}$ and to attempts to develop agreed clinical indications for procedures. ${ }^{30}$ The influence of social class continues to be explored, with results that usually disturb $^{31}$ but sometimes reassure. ${ }^{32}$

Infectious diseases apart, the burden of illness in a population changes very slowly, but health services struggle to keep up with changes in medical practice. This is obvious enough when new drugs or technologies are introduced, but changes in the indications for quite commonplace procedures can have a dramatic impact: between 1980 and 1987 the number of total hip replacements done in the USA
- one of the costliest Medicare procedures increased by more than $90 \%$, mostly because of an upward shift in the age distribution of patients, and with an increase in the number of patients operated on who had serious co-morbidities such as cancer or dementia. ${ }^{33}$ It seems likely that vascular surgery is undergoing a similar shift at present in the UK (E.G. Jessop, unpublished observations). Use of another in-patient procedure - caesarean section seems to be levelling off in many countries, though typically the data from England are of such poor quality as to be useless. ${ }^{34} \mathrm{~A}$ study in Oxford has documented the changing face of AIDS, from an illness that, perhaps through its newness, needed lengthy treatment under close supervision in hospital, to a spectrum of maladies associated with human immunodeficiency virus infection treated by brief episodes of in-patient care..$^{35}$

\section{Economic evaluation}

Much as one hates to admit it, money is usually in short supply. Furthermore, greater spending does not always mean more service. One function of health services research is to inform us how to get the most for patients from the funds available. Studies of cost effectiveness and cost utility require great attention to method and detail, if the results are not to be misleading - attention that is all too often lacking. ${ }^{36}$ Sometimes clinical audit indicates a way of achieving the same result with less use of expensive resources, for example, a reduction in intensive care after cardiac surgery. ${ }^{37}$

\section{A notable absence}

There have so far been few scientific publications on what was perhaps the greatest change in health service organization anywhere in the Western world for 50 years: the split between providers of health care and those who assign funding ('purchasers' or 'commissioners') in the NHS. Bradlow and Coulter looked at two aspects of one component: general practitioner fund holding. They found no support for the fear that budgetary pressures would affect general practitioners referral behaviour ${ }^{38}$ but they did confirm managers' gossip that fund holders were proving more effective than non-fund holders in controlling prescribing costs. ${ }^{39}$ More thought-provoking, however, was the sheer scale of increase in prescribing costs in both groups: $10 \%$ for fund holders and $19 \%$ for non-fund holders in just 12 months.

Increases at this rate are plainly, as the Secretary of State put it, 'unsustainable', hence the profusion of formularies, guidelines and protocols that attempt to steer general practitioners and others into cost-effective prescribing. Unfortunately, 
however, guidelines afford another example of the need for knowledge-based practice among those who manage health services, for the evidence is that guidelines are in general a poor way to change what doctors do ${ }^{40.41}$ Worse still, management practices, like clinical practices, can have unexpected adverse effects. One study in the USA concluded that the introduction of hospital formularies was accompanied by an increase in length of stay, perhaps because it took longer to give patients effective but second-line drugs. ${ }^{42}$ Those who produce guidelines usually write them and then forget them, paying no attention to the practicalities of getting their guidelines adopted by the clinicians at whom they are aimed. A distinguished exception is a booklet from the Royal College of Radiologists on the "how to' of introducing guidelines that will work ${ }^{43}$ This represents the fruit of a series of studies conducted over many years (for example, Royal College of Radiologists Working Party ${ }^{44}$ ).

\section{Conclusion}

We do need health services research to acquire the knowledge that will allow us to organize and manage health services to achieve the best for patients. This task is not easy but it is important. Every time I hear of someone whom the NHS has failed, I am reminded of Edward VII's famous comment on tuberculosis 'If preventable, why not prevented?'. Health services should not fail people in their time of need: when they do it is often a failure of organization. Acquiring knowledge of how best to organize health services is important for patients.

\section{References}

1. Secretary of State for Health. The Health of the Nation. $\mathrm{Cm}$ 1986. HMSO, London, 1992.

2. Hart, J.T., Thomas, C., Gibbons, B. et al. Twenty five years of case finding and audit in a socially deprived community. $\mathrm{Br}$ Med J 1991, 302: 1509-1513.

3. Imperial Cancer Research Fund OXCHECK Study Group. Effectiveness of health checks conducted by nurses in primary care: results of the OXCHECK study after one year. Br Med J 1994, 308: 308-312.

4. Family Heart Study Group. Randomised controlled trial evaluating cardiovascular screening and intervention in general practice: principal results of British family heart study. Br Med J 1994, 308: 313-320.

5. Hedrick, S.C. \& Branch, L.G. (eds) Adult day health care evaulation study. Med Care 1993, 31 (Suppl): SS1-SS124.

6. Leff, J. (ed.). The TAPS project: evaluating community placement of long-stay psychiatric patients. $B r J$ Psychiat 1993, 162 (Suppl 19): 1-56

7. Steiner, C.A., Bass, E.B., Talamini, M.A., Pitt, H.A. \& Steinberg, E.P. Surgical rates and operative mortality for open and laparoscopic cholecystectomy in Maryland. $N$ Engl J Med 1994, 330: 403-408.

8. Harding, M.J., Paul, J., Gillis, C.R. \& Kay, S.B. Management of malignant teratoma: does referral to a specialist unit matter? Lancet 1993, 341: 999-1002.

9. Laffel, G.L., Barnett, A.I., Finkelstein, S. \& Kay, M.P. The relation between experience and outcome in heart transplantation. N Engl J Med 1992, 327: 1220-1225.

10. Al-Haider, A.S. \& Wan, T.T.H. Modeling organisational determinants of hospital mortality. Health Services Res 1991, 26: 303-323.

11. Burns, L.R. \& Wholey, D.R. The effects of patient, hospital and physician characteristics on length of stay and mortality. Med Care 1991, 29: 251-271.

12. Rowan, K.M., Kerr, J.H., Major, E., McPherson, K., Short, A. \& Vessey, M.P. et al. Intensive Care Society's APACHE II study in Britain and Ireland - I: Variations in case mix of adult admissions to general intensive care units and impact on outcome. Br Med J 1993, 307: 972-977.

13. Dubois, R.W., Rogers, W.H., Moxley, J.H., Draper, D. \& Brook, R.H. Hospital inpatient mortality. $N$ Engl Med $J$ 1987, 317: 1674-1680.

14. Green, J., Passman, L.J. \& Wintfield, N. Analysing hospital mortality. The consequences of diversity in patient mix. JAMA 1991, 265: 1849-1853.
15. Tarnow-Mordi, W., Ogston. S., Wilkinson, A.R., Reid, E., Gregory, J., Saeed, M. \& Wilkie. R. Predicting death from initial disease severity in very low birthweight infants: a method for comparing the performance of neonatal units. $\mathrm{Br}$ Med J 1990, 300: 1611-1614.

16. Stiller, C.A. Survival of patients with cancer. Br Med J 1989 , 299: $1058-1059$.

17. Bowling, A. Measuring Health. A Review of Quality of Life Measurement Scales. Open University Press, Milton Keynes, 1991.

18. Hunt, S.M., McEwen, J. \& McKenna, S.P. Measuring Health Status. Croom Helm, London, 1986.

19. Jenkinson, C., Wright, L. \& Coutier, A. Quality of Life Measurement in Health Care: A Review of Measures and Population Norms for the SF-36. Health Services Research Unit, Oxford, 1992.

20. Phillips, R.C. \& Lansky, D.J. Outcomes management in heart valve replacement surgery: early experience. $J$ Heart Valve Dis 1992, 1: 42-50.

21. Cleary, P.D., Fowler, F.J., Weissman, J. et al. Health-related quality of life in persons with acquired immune deficiency syndrome. Med Care 1993, 31: 569-580.

22. Bjelle, A. Functional status assessment. Curr Opin Rheumatol 1991, 3: 280-285.

23. Rondinelli, R.D., Murphy, J.R., Wilson, D.H. \& Miller, C.C. Predictors of functional outcome and resource utilisation in inpatient rehabilitation. Arch Phys Med Rehabil 1991, 72: 447-453.

24. Malec, J.F., Smigielski, J.S., DePompolo, R.W. \& Thompson, J.M. Outcome evaluation and prediction in a comprehensive-integrated post-acute outpatient brain injury rehabilitation programme. Brain Injury 1993, 7: 15-29.

25. Conway, A.S., Melzer, D. \& Hale, A.S. The outcome of targeting community mental health services: evidence from the West Lambeth schizophrenia cohort. Br Med J 1994, 308: 627-630.

26. Price, C.E., Paul, E.A., Bevan, R.G. \& Holland, W.W. Equity and medical practice variation: relationships between standardised discharge ratios in total and for selected conditions in English districts. J Epidemiol Community Health 1992, 46: 58-62.

27. Burney, P.G.J., Papacosta, A.O., Withey, C.H., Colley, J.R.T. \& Holland, W.W. Hospital admission rates and the prevalence of asthma symptoms in 20 local authority districts. Thorax 1991, 46: 574-579. 
28. Payne, J.N., Coy, J., Patterson, S. \& Milner, P.C. Is use of hospital services a proxy for morbidity? A small area comparison of the prevalence of arthritis, depression, dyspepsia, obesity and respiratory disease with inpatient admission rates for these disorders in England. J Epidemiol Community Health 1994, 48: 74-78.

29. Hopkins, A. \& Wallace, P. (ed.). Referrals to Medical Outpatients. Royal College of Physicians, London, 1992.

30. Hunter, D.J.W., McKee, C.M., Sanderson, C.F.B. \& Black, N.A. Appropriate indications for prostatectomy in the UK results of a consensus panel. J Epidemiol Community Health 1994, 48: 58-64.

31. Kelly. W.F., Mahmood, R., Kelly, M.J., Turner, S. \& Elliott, $K$. Influence of social deprivation on illness in diabetic patients. Br Med J 1993, 307: 1115-1116.

32. Kee, F., Gaffny, B., Currie, S. \& O'Reilly, D. Access to coronary catheterisation: fair shares for all? $\mathrm{Br}$ Med J 1993 , 307: 1305-1307.

33. Friedman, B. \& Elixhauser, A. Increased use of an expensive, elective procedure: total hip replacements in the 1980s. Med Care 1993, 7: 581-599.

34. Macfarlane, A. \& Chamberlain, G. What is happening to caesarean section rates? Lancet 1993, 342: 1005-1006.

35. O'Brien, S.J., Burch, J. \& Mayon-White, R.T. Hospital bed usage by people with HIV disease: experience in a provincial setting. Public Health 1993, 107: 355-362.
36. Mason, J., Drummond, M. \& Torrance, G. Some guidelines on the use of cost effectiveness league tables. Br Med J 1993 , 306: $570-572$.

37. Chong, J.L., Rillar, R., Fisher, A., Grebenik, C., Sinclair, M. \& Westaby, S. et al. Cardiac surgery: moving away from intensive care. Br Heart J 1992, 68: 430-433.

38. Coulter, A. \& Bradlow, J. Effect of NHS reforms on general practitioners' referral patterns. Br Med J 1993, 306: 433-437.

39. Bradlow, J. \& Coulter, A. Effect of fundholding and indicative prescribing schemes on general practitioners' prescribing costs. Br Med J 1993, 307: 1186-1189.

40. Grimshaw, J.M. \& Russell, I.T. Effect of clinical guidelines on medical practice: a systematic review of rigorous evaluations. Lancet 1993, 342: 1317-1322.

41. Axt-Adam, P., van der Wouden, J.C. \& van der Does, E. Influencing behavior of physicians ordering laboratory tests: a literature study. Med Care 1993, 31: 784-794.

42. Sloan, F.A., Gordon, G.S. \& Cocks, D.L. Hospital drug formularies and use of hospital services. Med Care 1993, 31: $851-867$.

43. Field, S. A Protocol for the Effective Implementation of Guidelines to Good Radiological Practice. Royal College of Radiologists, London, 1993.

44. Royal College of Radiologists Working Party. Influence of Royal College of Radiologists' guidelines on referral from general practice. $\mathrm{Br}$ Med J 1993, 306: 110-111. 